\title{
Padê Editorial e Nega Lilu: representatividade feminina no mercado editorial independente
}

\author{
Padê Editorial and Nega Lilu: Female Representation \\ in the Independent Publishing Market \\ Padê Editorial y Nega Lilu: representación femenina \\ en el mercado editorial independiente \\ Maria do Rosário A. Pereira* \\ Samara Mirian Coutinho*
}

\begin{abstract}
Resumo
Este artigo propõe-se a apresentar algumas considerações sobre duas editoras brasileiras pertencentes ao chamado mercado independente: Padê Editorial, fundada em 2015, e Nega Lilu, em 2013. Primeiramente, destacam-se alguns conceitos importantes para se pensar a cena independente, tais como o de "campo editorial", de Pierre Bourdieu, e a própria noção de "independência", ligada à busca por práticas editoriais que priorizam a bibliodiversidade, na busca por alternativas mercadológicas que não coloquem o lucro como principal finalidade. O escopo teórico do artigo está ancorado em John Thompson (2013), Gilles Colleu (2007) e José Muniz Jr. (2016). A seguir, é realizado o estudo de caso das editoras aqui elencadas, ao conferirem visibilidade às mulheres, às mulheres negras e às lésbicas, principalmente, além de estarem situadas fora do eixo Rio de Janeiro-São Paulo, dando visibilidade, ainda, aos autores da região CentroOeste, onde estão localizadas. Assim, tais práticas editoriais, que objetivam, inclusive, um apelo estético significativo, acabam por adquirir uma significação política, tornando-se capitais simbólicos primordiais para se pensar (e repensar) o cenário contemporâneo da edição no Brasil.
\end{abstract}

Palavras-chave: mercado editorial independente, Padê Editorial, Nega Lilu, editoras mulheres.

\section{Abstract}

This paper aims to present some considerations about two Brazilian publishing houses which belong to the so-called independent market: Padê Editorial, founded in 2015, and Nega Lilu, founded in 2013. Firstly, we will highlight some important concepts concerning the independent scene, such as Pierre Bourdieu's "editorial field" and the very notion of "independence," linked to the search of editorial practices that prioritize bibliodiversity, seeking market alternatives in which profit is not their main concern. The article's theoretical basis is rooted in John Thompson (2013), Gilles Colleu (2007) and José Muniz Jr. (2016). Afterwards, a case study of the publishers listed here is made, mainly promoting the visibility of women, black women and lesbians, as well as those located outside the Rio de Janeiro-São Paulo hub; They also promote visibility of female authors from the Midwest region of Brazil where the companies are based.

\section{Resumen}

Este artículo propone presentar algunas consideraciones sobre dos editoriales brasileñas que pertenecen al llamado mercado independiente: Padê Editorial, fundada en 2015, y Nega Lilu, en 2013. En primer lugar, se destacan algunos conceptos importantes para pensar sobre la escena independiente, como el "campo editorial", de Pierre Bourdieu, y la noción misma de "independencia", vinculada a la búsqueda de prácticas editoriales que prioricen la biodiversidad, en la búsqueda para alternativas de marketing que no tienen como objetivo principal el beneficio. El alcance teórico del artículo está anclado en John Thompson (2013), Gilles Colleu (2007) y José Muniz Jr. (2016). A continuación, se realiza el estudio de caso de las editoriales enumeradas aquí, ya que dan visibilidad a las mujeres, las mujeres negras y las lesbianas, principalmente, además de ubicarse fuera del eje Río de Janeiro-São Paulo, dando visibilidad, también, a los autores de la región del "Centro-

\footnotetext{
* Centro Federal de Educação Tecnológica de Minas Gerais (CEFET-MG), Belo Horizonte, MG, Brasil. (Dorcid.org/0000-00024797-5724. E-mail: mariadorosario58@gmail.com

** Centro Federal de Educação Tecnológica de Minas Gerais (CEFET-MG), Belo Horizonte, MG, Brasil. (Dorcid.org/0000-00023956-4087. E-mail: samaramirian88@gmail.com
} 
Therefore, such editorial practices which aspire to even a significant aesthetic appeal, end up acquiring a political importance as well, becoming primordial symbolic capitals to think (and rethink) the contemporary publishing scenario in Brazil.

Keywords: independent editorial market, Padê Editorial, Nega Lilu, women publishers.
Oeste", donde se encuentran. Así, estas prácticas editoriales, que presentan un atractivo estético significativo, terminan adquiriendo un significado político, convirtiéndose en capitales simbólicos primordiales para pensar (y repensar) el escenario contemporáneo de la publicación en Brasil.

Palabras-clave: mercado editorial independiente, Padê Editorial, Nega Lilu, editoras.

\title{
O campo da edição independente
}

\author{
Seguiré aventurándome, cambiando abriendo la mente y los ojos. \\ Me niego a ser etiquetada o estereotipada. \\ Hay que liberarse sin restricción para descubrir nuevas dimensiones.
}

Virginia Woolf, Diario de una escritora (1953)

Os estudos relativos ao campo da edição passam, atualmente, por uma série de fontes distintas, numa espécie de interseção entre diversas áreas do conhecimento, como história, sociologia, economia e ciências da informação e da comunicação, conforme apontado por Sophie Nöel em La edición independiente crítica: compromisos políticos e intelectuales (2018, p. 15). Isso implica que o campo da edição encontra-se em uma "posição estratégica", a saber, mobiliza uma série de saberes da ordem do intelectual, do político, do cultural. Ressalte-se que tomamos como referência para a noção de "campo" o que é preconizado por Pierre Bourdieu em $A$ produção da crença (2001), ao apontar que campo diz respeito a um espaço no qual agentes e instituições buscam alcançar determinadas posições de prestígio a partir de suas relações e das disputas que ali se engendram. $\mathrm{O}$ prestígio galgado permite, principalmente por meio do acúmulo de capital simbólico, legitimar certas representações como válidas - o que é chamado pelo sociólogo de "poder de consagração".

É válido ressaltar que o campo editorial, apesar de ser "relativamente dependente, em especial ao campo econômico e ao campo político" (Bourdieu, 2005, p. 162), possui suas próprias "regras do jogo", com uma lógica particular norteadora das condutas dos agentes que o compõem. Jonh B. Thompson, em Mercadores de cultura, afirma que, dentro do mundo editorial, há "uma pluralidade de campos, cada qual com suas características distintas" (2013, p. 10) e, em cada um deles, há uma complexa rede de poder e interdependência que se estrutura em torno dos capitais acumulados. ${ }^{1}$

Entre estes "subcampos" figura o da edição independente, de difícil delimitação devido à multiplicidade semântica do termo "independente". Neste artigo vamos considerá-lo dentro do espectro apontado por José de Souza Muniz Jr. (2016), em Girafas e bonsais: editores "independentes" na Argentina e no Brasil (1991-2015). Ao referir-se ao circuito independente como um todo, o autor afirma:

Em termos muito gerais, a produção cultural independente será concebida como aquela que está fora - ora por escolha, ora por condição - dos circuitos e mercados massivos; que não adota as lógicas dos grandes conglomerados de cultura e mídia; que se identifica com métodos artesanais de produção, com o experimentalismo estético e/ou com discursividades dissonantes, alternativas, contra-hegemônicas. Ao mesmo tempo que se opõe implicitamente ao dependente (ou seja, aos agentes e às práticas culturais subordinados a tais lógicas), esse produtor se definirá a contrapelo de certos carrascos da dependência - o mercado, o mainstream, as empresas privadas, os grandes conglomerados,

\footnotetext{
${ }^{1} \mathrm{O}$ uso do termo "capitais", frequente na obra de Pierre Bourdieu, foi tomado de empréstimo à Economia e refere-se aos recursos que um indivíduo ou uma corporação possuem no campo social. Thompson se apropria de tais termos e subdivide-os em capital econômico, humano, social, intelectual e simbólico, visando à aplicação no estudo do mercado editorial (Thompson, 2013, p. 11).
} 
as instâncias públicas etc. que controlam a produção, a circulação e a consagração dos bens simbólicos (Muniz Jr., 2016, p. 16).

O autor chama a atenção para o fato de que, nos últimos anos, muitos bens culturais e muitos sujeitos, em diversos cenários - música, cinema, literatura etc. -, têm se valido dessa nomenclatura numa tentativa de caracterização que se oponha à cultura dominante e que fundamente uma lógica de produção própria, ancorada na originalidade, e não na mera reprodução de padrões para consumo em massa. Em relação ao mercado editorial especificamente, os "livros-produto", em expressão de Gilles Colleu (2007, p. 17) em Editores independentes: da idade da razão à ofensiva?, alimentam um mercado que anseia por um retorno em curto prazo de seus investimentos financeiros; já os "livros de criação" procuram tornar o mercado mais diverso, mais inclusivo, ao trazer à cena obras pouco ou nada valorizadas por apresentarem vozes, pontos de vista ou mesmo formatos que destoam do pensamento capitalista e das práticas de produção vigentes, fomentando a chamada bibliodiversidade:

A bibliodiversidade é uma noção concreta que aplica o conceito de biodiversidade [...] ao livro [...]. Ela remete à necessária diversidade das produções editoriais disponibilizadas para o público. O livro de criação é a encarnação da bibliodiversidade, opondo-se ao fenômeno da "best-sellerização" (produção editorial que se baseia essencialmente em produtos produzidos para o maior número, representando uma tomada de risco mínima, e respondendo essencialmente a objetivos financeiros) (Colleu, 2007, p. 20, nota 2).

Colleu entende por "livro de criação" justamente o livro que é produzido no circuito independente, no qual os catálogos são pensados não para atender a interesses imediatistas, e sim para durarem, isto é, sua significação cultural é mais importante do que sua rentabilidade. Para o grande mercado, o conteúdo é o menos importante; para o mercado independente, é aí, em seu potencial cultural e ideológico, que reside a relevância maior de uma obra.

É válido aqui um adendo: essa lógica antagonizante, que divide os editores entre fiadores da cultura versus agentes comerciais, é decorrente das peculiaridades do mercado de bens artísticos no qual a denegação é a prática norteadora dos produtores de arte. Por denegação entende-se que "não é uma negação real do interesse 'econômico' que assombra continuamente as práticas mais desinteressadas, nem uma simples dissimulação dos aspectos mercantis da prática" (Bourdieu, 2001, p. 21), mas um "recalcamento constante e coletivo do interesse propriamente econômico" (p. 19), ou seja, uma das principais "regras do jogo" é a recusa de reconhecer publicamente que muitos objetos artísticos são feitos para auferir lucros também. Aos editores cabe a figura de banqueiros culturais, que mercantilizam a produção de artistas, dividindo-se no interstício de dois polos: aqueles que denegam o fator financeiro tanto quanto os artistas, e aqueles que se posicionam como agentes estritamente comerciais.

Quando nos referimos ao campo da edição independente, observa-se que este tem como característica uma grande tendência ao polo da denegação, inclusive pela grande quantidade de obras autopublicadas. Em contrapartida, propõe-se a ser mais dinâmico, mais engajado, uma vez que menos atrelado e comprometido com o mercado financeiro; por não ser tão devedor do capital, consegue manter uma autenticidade maior no que se refere à sua representatividade enquanto capital simbólico. E é justamente neste campo que se enquadram as duas editoras selecionadas para análise neste trabalho: Padê Editorial e Nega Lilu.

Ambas são editoras criadas por mulheres e surgiram com o intuito de publicar as obras de suas idealizadoras, Tatiana Nascimento e Bárbara Esmenia (Padê), e Larissa Mundim (Nega Lilu). Isso aponta para a importância da autopublicação no mercado independente e, ao mesmo tempo, para o fato de autor e editor convergirem numa mesma figura. Além disso, no catálogo das duas editoras, é possível perceber uma tendência a agregar autores "marginalizados" no mercado editorial - ou por serem completos desconhecidos ou, ainda, por retratarem temáticas "espinhosas", que incomodam o status quo. É assim que a maioria das autoras da Padê são negras, além de serem lésbicas, e o catálogo da Nega Lilu, ainda que mais eclético, engloba majoritariamente também autoras mulheres e goianas (o espaço e a cultura goianas têm grande relevância nas obras editadas). Em muitos livros figuram, ainda, temáticas nada canônicas, 
como a própria lesbianidade, a transsexualidade etc. Destaque-se também o apuro estético que permeia a produção das duas casas editoriais: obras extremamente bem realizadas do ponto de vista gráfico e artístico. Outro ponto de confluência entre as duas editoras diz respeito a sua localização geográfica: ambas estão fora da região Sudeste: a Padê, no Distrito Federal; e a Nega Lilu, em Goiânia. A seguir, destacaremos alguns aspectos para a compreensão do lugar de relevância ocupado por essas editoras em um mercado editorial pouco diverso.

\title{
Padê Editorial
}

\author{
padê surge das encontras. das caminhas \\ encruzilhadas. [...] \\ padê materializa em letras a ânsia-preta- \\ não-dá-mais-pra-segurar. \\ padê quer ser registra escrita. objeta \\ tocável. propícia ao olfato. \\ gustativas palavras. sensitivo pensar. \\ padê pá que é nóis.
}

Disponível em: pade.lgbt/sobre/

Fundada em 2015 por Tatiana Nascimento dos Santos e Bárbara Esmenia, a Padê Editorial cumpre uma importante função ao trazer à baila livros de temática lésbica escritos por mulheres lésbicas - e também bissexuais, transsexuais e transgêneros -, em sua maioria negras. ${ }^{2}$ Na página de créditos de seus livros, lê-se: "padê editorial é um coletivo editorial artesanal que publica autoras negras y/ou lgbtqi+, fundado por tatiana nascimento y Bárbara Esmenia, em brasília/DF." Ressalte-se a originalidade desse projeto editorial, precedido, no Brasil, pela Editora Brejeira Malagueta, fundada em 2008 por Laura Bacellar e Hanna Korich, e extinta em 2015, a qual se autoproclamava "a primeira editora lésbica na América Latina". ${ }^{3}$ No entanto, a Padê acrescenta a variável racial a suas publicações, agregando um novo elemento para se refletir sobre o papel ocupado por essa pequena editora em um cenário um tanto quanto excludente.

O uso reiterado de minúsculas em nomes próprios indica uma clara conotação política por parte da editora, cujo projeto insere-se na perspectiva de desconstrução de um cânone literário e de um mercado editorial extremamente concentrado no Brasil. Tal concentração é perceptível em pesquisas como a de Regina Dalcastagnè em Literatura brasileira: um território contestado (2012). De acordo com a professora e pesquisadora, como o que está em jogo é a possibilidade de dizer sobre si e sobre o mundo que nos cerca, ou seja, o poder de falar com legitimidade, a emergência de vozes até então abafadas historicamente, "não autorizadas", gera um desconforto em um campo literário ainda extremamente homogêneo como o brasileiro. Após extensa pesquisa envolvendo docentes e discentes da Universidade de Brasília, chegou-se à conclusão de que quase 73\% dos autores que publicaram romances de 1990 a 2004, pelas principais editoras brasileiras, eram homens; quase $94 \%$, brancos; e mais de $60 \%$, residentes no eixo Rio de Janeiro-São Paulo (2012, p. 8).

Sendo assim, uma proposta editorial como a da Padê aponta para uma tripla representatividade e uma tripla transgressão nesse sentido: ${ }^{4}$ marca-se uma posição no que se refere ao "lugar de fala", isto é, são ouvidas as vozes historicamente silenciadas de mulheres, em primeiro lugar; em segundo, trata-se de mulheres que estão fora da heteronormatividade,

\footnotetext{
${ }^{2}$ De acordo com o site da editora, "75\% dxs autorxs se autodeclaram negrxs". Disponível em: pade.lgb/escrevivencias. Acesso em: 16 mar. 2020.

${ }^{3} \mathrm{Na}$ apresentação em seu site, lia-se: “Achamos necessário criar uma editora lésbica porque a maioria das editoras por aí - aliás, a maioria de tudo o que existe por aí - nos ignora solenemente ou então publica absurdos a nosso respeito. [...] E já assistimos coisas demais serem colocadas na nossa boca, opiniões e achismos que nos atribuíram sem nos perguntarem nada antes. Chega disso, não?” Disponível em: www.editoramalagueta.com.br (apud Silva, 2016, p. 88).

${ }^{4}$ O "triplo fardo", conforme Westwood (1984 apud Kilomba, 2019, p. 98).
} 
pois, sendo lésbicas, os papéis tradicionais de "mãe" e "esposa" não mais lhes são impostos; e, finalmente, transgridem-se as normas vigentes com um terceiro elemento, o racial. Isso porque as mulheres negras ocupam um "espaço vazio, um espaço que se sobrepõe às margens da 'raça' e do gênero" (Mirza, 1997 apud Kilomba, 2019, p. 97), uma vez que as mulheres negras enfrentam preconceitos e situações de exclusão e violência ainda maiores que as das mulheres brancas e que se distinguem das vivências do homem negro. ${ }^{5}$

Assim, os livros editados pela Padê criam "geografias desviantes", em expressão de Natália Borges Polesso (2018, p. 3), pois se questionam ao mesmo tempo modelos estabelecidos de representação - uma vez que a produção literária das mulheres lésbicas apresenta personagens distantes das representações femininas estereotipadas e consagradas na literatura tout court -, bem como de autoria, já que também as autoras lésbicas negras (que colocam tanto a experiência lésbica como a negra em seus textos) têm pouca evidência no mercado editorial.

Destacamos também o fato de as publicações apresentarem caráter artesanal, sendo produzidas dentro da proposta das cartoneras, tipo de publicação de baixo custo que utiliza papelão na capa, sendo que cada capa pode ser customizada de uma maneira própria, tornando a obra quase exclusiva - ainda que, diferentemente de muitas editoras cartoneras, a Padê tenha optado por manter sempre a mesma capa para o mesmo livro, provavelmente com o intuito de conferir uma identidade visual maior às obras, reiterando a proposta de "coleção". Na Padê, há uma coleção que se utiliza exclusivamente desse formato de cartonera, resultado do \#ProjetoEscrevivências, cujas publicações foram editadas de julho de 2018 a julho de 2019: a "cole-sã escrevivências":

Inspirada nas escrevivências elaboradas/teorizadas por conceição evaristo, a cole-sã escrevivências, da padê editorial, é dedicada a textos maravilhantes de literatura lgbtqi+ (majoritariamente) negra contemporânea. são mais de 60 títulos de autorxs sapatonas, travestis, mulheres y homens trans, gente não-binária, povo preto sexual-dissidente de um monte de lugares num brasil que insiste em nos matar, nos impedir de sonhar, de falar com nossa própria voz. mas mesmo assim: aqui estamos, falamos, escrevemos. sonhamos!

Nesse texto de apresentação da referida coleção, escrito por sua curadora - Tatiana Nascimento, também idealizadora do portal www.literatura.lgbt -, fica evidente o objetivo político que envolve tais projetos, em uma sociedade que "tenta nos roubar de nossas palavras [...] colonizando nossa expressão/discurso/narrativas". Tal perspectiva insere-se no que o feminismo vem chamando de "feminismo decolonial", o qual aponta para uma "hierarquia dicotômica entre seres humanos e não humanos" como a "dicotomia central da modernidade colonial", nas palavras de María Lugones em "Rumo a um feminismo decolonial" (2019, p. 358). O humano seria, sobretudo, o homem "europeu, burguês, [...] heterossexual, cristão, um ser da mente e da razão", ao passo que o não humano seria aquele ligado ao bestial, o negro colonizado, enfim. Ainda que a teoria de Lugones seja mais complexa do que isso, vale a pena destacar sua definição de "colonialidade":

Uso o termo colonialidade para nomear não apenas uma forma de classificar pessoas através de uma colonialidade do poder e dos gêneros, mas também para pensar sobre o processo ativo de redução das pessoas, a desumanização que as qualifica para a classificação, o processo de subjetivação, a tentativa de transformar o colonizado em menos que humano. (Lugones, 2019, p. 361)

Sendo "menos que humano", o que resta ao negro e, especificamente, à mulher negra? Para Lugones, "decolonizar os gêneros é necessariamente uma práxis" (2019, p. 363), ou seja, é necessária a ação. É assim que um coletivo editorial que traga à luz publicações de mulheres negras e lésbicas fratura o sistema, mostrando: i) a mobilização de todo um coletivo como prática de resistência, ou formas de "resistência em ação", nas palavras de Noël (2018, p. 9); ii) a importância de tais práticas em um movimento maior de visibilidade, ainda que, conforme

\footnotetext{
5 "Mulheres negras têm sido, portanto, incluídas em diversos discursos que mal interpretam nossa própria realidade: um debate sobre racismo no qual o sujeito é o homem negro; um discurso genderizado no qual o sujeito é a mulher branca; e um discurso de classe no qual 'raça' não tem nem lugar. Nós ocupamos um lugar muito crítico dentro da teoria” (Kilomba, 2019, p. 97).
} 
destaca Dalcastagnè (2012), práticas e espaços não sejam valorados da mesma forma, o que significa dizer que uma editora independente como a Padê não tenha obviamente o alcance de uma grande editora. Ainda assim, é necessário que se busquem estratégias para publicar e chegar até os leitores, pois só assim a edição constitui-se como tarefa efetiva de resistência:

Ninguém resiste à colonialidade dos gêneros sozinho. Somente é possível resistir a ela com o entendimento do mundo e com uma vivência que é compartilhada e consegue entender as próprias ações - garantindo certo reconhecimento. As comunidades, e não os indivíduos, possibilitam o fazer; as pessoas produzem junto de outras, nunca em isolamento (Lugones, 2019, p. 372).

Em entrevista, Tatiana Nascimento corrobora a afirmação de Lugones, ao apontar para a identificação existente entre o leitor e a publicação, pois este, além de se ver representado, pode sentir-se encorajado também ele a publicar, a tornar-se um autor:

a maioria das pessoas que compram nossos livros são pessoas lgbtqi e/ou negras. que ficam muito felizes de saber que tem essa editora, que faz livros lindos (por fora y por dentro!) de autoras negras, de pessoas lgbtqi. as pessoas se espelham, veem inclusive possibilidade de serem publicadas a partir disso (Nascimento, 2018, p. 69).

Sendo assim, um dos propósitos da editora é a inclusão e, logo, torna-se um instrumento político a serviço dos direitos humanos, algo fundamental nos dias de hoje. $\mathrm{O}$ fomento à bibliodiversidade, na busca por uma proposta editorial que abarque a diversidade de experiências de mulheres que se reconhecem como negras e se assumem como lésbicas, fica claro ainda pelo fato de a cole-sã escrevivências ter licença Creative Commons, isto é, o material pode ser compartilhado em qualquer suporte ou formato, desde que a autoria seja atribuída e que não seja para uso comercial. Destaque-se ainda que os títulos da cole-sã podem ser encontrados para download gratuito no portal www.literatura.lgbt.

O formato mais sustentável do ponto de vista ambiental não é perceptível somente nas capas de papelão. Como exemplo, tem-se o terceiro livro publicado pela editora, Interiorana, da poeta Nívea Sabino, de Nova Lima (Minas Gerais). Lançado em 2016, com tiragem de 200 exemplares esgotada, foi feito com miolo em papel reciclado. A capa, assinada pelo artista brasiliense Jupiter Koroá, com impressão em serigrafia, conferia um ar de originalidade, destacando, ao mesmo tempo, o caráter artesanal da publicação, que saiu pela cole-sã Odoyá.

No que se refere à produção propriamente dita, um dos maiores gargalos para editoras pequenas está na questão do financiamento e da distribuição. Nota-se que a Padê se sustenta, ao menos em parte, por financiamento via editais públicos. A cole-sã em estudo foi selecionada pelo Fundo Elas de Investimento Social, em 2018. No que diz respeito à divulgação e à distribuição das obras, Tatiana Nascimento afirma:

somos uma editora bem pequena. editora-feirante. não vamos muito atrás de público, lançamos os livros, divulgamos nas redes sociais, fazemos saraus de lançamento, levamos pras feiras; as autoras saem com eles por aí divulgando, vendendo. não temos muito um plano estratégico de vendas, infeliz ou felizmente. (Nascimento, 2018, p. 81)

Essa ideia da "editora-feirante" reitera a importância de os pequenos editores participarem de feiras e eventos que se proponham a divulgar esse tipo de trabalho, e mesmo de fazerem parcerias entre si. Larissa Mundim, quando expõe os livros da Nega Lilu em feiras, por exemplo, costuma levar os da Padê consigo. Esse fato demonstra a importância das redes de sociabilidade entre os pequenos produtores culturais, nos mais diversos segmentos, uma vez que isso pode impulsionar o setor como um todo. A presença dessas editoras em feiras é uma itinerância que acarreta efeitos em longo prazo, porque

interfere sobre as representações que os outros agentes têm desse empreendimento e dos diversos empreendimentos uns com relação aos outros. Além disso, esses eventos caracterizam-se por dar espaço à circulação das pessoas, dos objetos e dos capitais que são acumulados, negociados e convertidos em cada um dos territórios simbólicos a que fazem referência (Muniz Jr., 2016, p. 188). 
É assim que os editores vão se conhecendo e estabelecendo contatos, fazendo parcerias e constituindo apoios que permitem uma ampliação do alcance de cada pequeno editor. Além disso, a participação em feiras no exterior também é aspecto significativo. Leve sua culpa branca pra terapia, terceiro livro de ensaios e primeiro em prosa de Tatiana Nascimento pela Padê, teve sua primeira edição, de 101 exemplares, confeccionada especialmente para a Feira Queeres Verlegen, em Berlim, Alemanha, em novembro de 2019. Trata-se de livro trilíngue, em português, espanhol e inglês, o qual aborda uma temática fulcral: os significados da branquitude e sua relação com o racismo. Também projetos sociais são iniciativas desta editora, como o projeto "Isso é Amor? Violência, relações abusivas \& relacionamentos saudáveis entre LBT's", de 2019, que objetivou prevenir e reconhecer a existência de relações abusivas nos grupos que figuram no título do projeto, bem como "construir formas ou tecnologias para afetos saudáveis entre nós" ${ }^{6} \mathrm{O}$ objetivo do projeto era, ainda, após discussões em oito encontros formativos abertos ao público e uma pesquisa com a comunidade LGBT+, confeccionar uma cartilha impressa, com distribuição gratuita, que auxiliasse de alguma forma esse público no combate à violência. Como se nota, há uma estreita ligação entre edição e práxis política, no sentido de estabelecer um diálogo com a comunidade e propor ações efetivas que melhorem a qualidade de vida das pessoas às quais as publicações se destinam.

É possível notar, ainda, uma relação entre o surgimento da Padê e outros movimentos culturais à margem da cena principal, como os slams, o que se pode depreender das palavras de Tatiana Nascimento:

eu y bárbara somos poetas, artistas da palavra falada; ela tinha vindo, a meu convite, participar de uma edição do slam das minas DF - que foi a primeira batalha de poesia exclusiva pra mulheres y lésbicas no brasil, idealizada por mim, cofundada por mim e val matos, uma outra ativista negra sapatão aqui do df. mesmo sem nos conhecermos bem, eu y bárbara fizemos esse combinado de montar uma editora "do jeito desse livro", só que pra publicar exclusivamente autoras negras y/ou pessoas lgbtqi, começando por nós mesmas. começamos a pensar nossos livros, cada qual em sua cidade, y a convidar autoras que gostaríamos de publicar. assim a padê foi gestada. y foi parida quando, em janeiro de 2016, bárbara comprou uma impressora pra imprimir o primeiro livro dela, \{penetra-fresta\}. como pra mim era muito importante que a editora que foi sonhada no df tivesse raízes produtivas também centro-oestinas, lancei concomitantemente o livro "esboço", em fevereiro de 2016, com poemas meus que estariam quase todos no "lundu,". foi uma tiragem pequena, de 35 exemplares (porque era ano de meu aniversário de 35), mas da qual a venda me permitiu juntar dinheiro pra publicar "lundu,", que saiu em março de 2016 (Nascimento, 2018, p. 50).

Várias informações importantes aqui aparecem: $i)$ muitas editoras pequenas começam seus trabalhos dentro da perspectiva da autopublicação - como não encontram chancela no mercado, autores montam sua própria editora; ii) a perspectiva do descentramento, no que se refere ao espaço geográfico - a vontade de contemplar uma região pouco visível editorialmente, o Centro-Oeste. Ambas poetas e participantes de slams, as fundadoras da Padê aliaram um interesse pessoal a um projeto coletivo.

Nessa empreitada, há que se considerar o próprio catálogo da editora como um instrumento criativo, muito bem pensado e concebido para contemplar tipos de obras distintas, que podem interessar tanto a um leitor comum quanto a um leitor mais especializado. O catálogo da Padê divide-se em três coleções: cole-sã Odoyá - dedicada à poesia e a Iemanjá, com 13 títulos; cole-sã Odara, uma obra - dedicada a temas em teatro; e cole-sã escrevivências, com 45 títulos publicados (dados de 2019 extraídos tanto do site da editora quanto de seu catálogo físico, distribuído em feiras de livros independentes), que perpassam diversos gêneros textuais, desde poesia (com ênfase em escritoras estreantes) até ensaios. Outro aspecto significativo é esse caráter da autoria: em geral, são autoras desconhecidas do público, as quais, geralmente, publicam uma obra pela primeira vez e que não têm suas demandas literárias contempladas pelo circuito das grandes editoras, o que reforça a ideia de bibliodiversidade mencionada anteriormente.

${ }^{6}$ Disponível em: http://bit.ly/3szZ8ob. Acesso em: 29 mar. 2020 
Quanto às tiragens e ao capital financeiro, no começo, muitas obras eram publicadas em tiragens especiais e, com o dinheiro, financiava-se uma tiragem maior - de 200 a 500 exemplares, em geral, exceto na cole-sã escrevivências, que tem tiragem de 44 exemplares para cada título. Algumas autoras tiveram uma segunda edição ampliada para 100 exemplares, edição esta financiada pela venda da primeira, não mais pelo edital do Fundo Elas, o que demonstra a autossustentabilidade do empreendimento. Também é a mesma situação do livro Esboço, cuja venda possibilitou o financiamento de outra obra de Tatiana Nascimento, conforme citação acima. Com o passar do tempo, a Padê legitima-se no circuito independente, conquistando a adesão de leitores e a cumplicidade de outros editores, o que reitera sua importância.

\section{Nega Lilu Editora}

É dessa forma que o efêmero, o imponderável e a incerteza da casualidade assumem protagonismo na condução desse trabalho inspirado na perversão de uma demanda ancestral do ser humano: devora-me ou decifro-te.

Larissa Mundim

A Nega Lilu Editora foi fundada em 2013, em Goiânia, capital de Goiás, pela escritora e jornalista Larissa Mundim, depois de se dedicar por 15 anos a mídias como o jornal, o rádio e a televisão: "comecei a trabalhar com literatura acalentando um sonho juvenil de publicar um livro. Então me autopubliquei". 7 Partindo desta vontade de se autopulicar, ela deu início a um projeto editorial que transita entre o mundo das artes visuais, da literatura e da militância cultural.

A origem do primeiro título, Sem palavras (2013), escrito pela editora e por Valentina Prado, possui uma história peculiar, tanto no conteúdo quanto em seus desdobramentos práticos. Com uma "arquitetura diferentona", como a editora gosta de se referir ao título, a história do romance entre Laura Passing (Nega) e Brisa Marin (Lilu) demonstra as sutilezas na troca de afeto de um relacionamento por meio da "correspondência trocada, e-mails e chats que vão construindo a narrativa a partir da estética e arquitetura próprias da comunicação mediada no ciberespaço" (Mundim e Prado, 2013, p. 9). Para transpor ao suporte físico a interação das protagonistas, foram usados ícones estabelecidos no imaginário coletivo de usuários das plataformas digitais, orientando o leitor sobre a origem do diálogo e expressando reações com emoticons.

Antes de publicar o impresso, Larissa Mundim criou um blog para testar o conto - finalizado em 2010 - com um grupo de leitores especializados de diferentes áreas de atuação. O feedback destes permitiu que o livro fosse lapidado, concomitantemente à realização de uma série de intervenções culturais relatadas no livro Operação KamiKaze (Mundim, 2015). Tais profissionais se uniram a outros, formando o Coletivo Esfinge, que chegou a mais de 100 participantes das intervenções que giravam em torno da obra literária. No diagrama retirado do livro (Figura 1), observamos uma representação esquemática das áreas mobilizadas pelas ações do coletivo em um balanço posterior ao lançamento do Sem palavras.

Tal esquema, presente no livro com a legenda "Representação final da rede, com exclusão de atividades não alavancadas, reordenamento e redimensionamento de ações consolidadas, com vistas ao registro da memória do projeto", permite-nos observar o grau de engajamento prévio ao lançamento da obra. A pré-venda iniciou antes da impressão e, em abril de $2014,50 \%$ da tiragem inicial foi comercializada (Mundim, 2015, p. 136). Na parte laranja que se refere ao eixo literatura, observamos que um dos resultados foi a fundação da editora, que leva o nome das protagonistas da obra.

\footnotetext{
${ }^{7}$ Em entrevista concedida a Samara Mírian Coutinho em 31 de maio de 2019.
} 


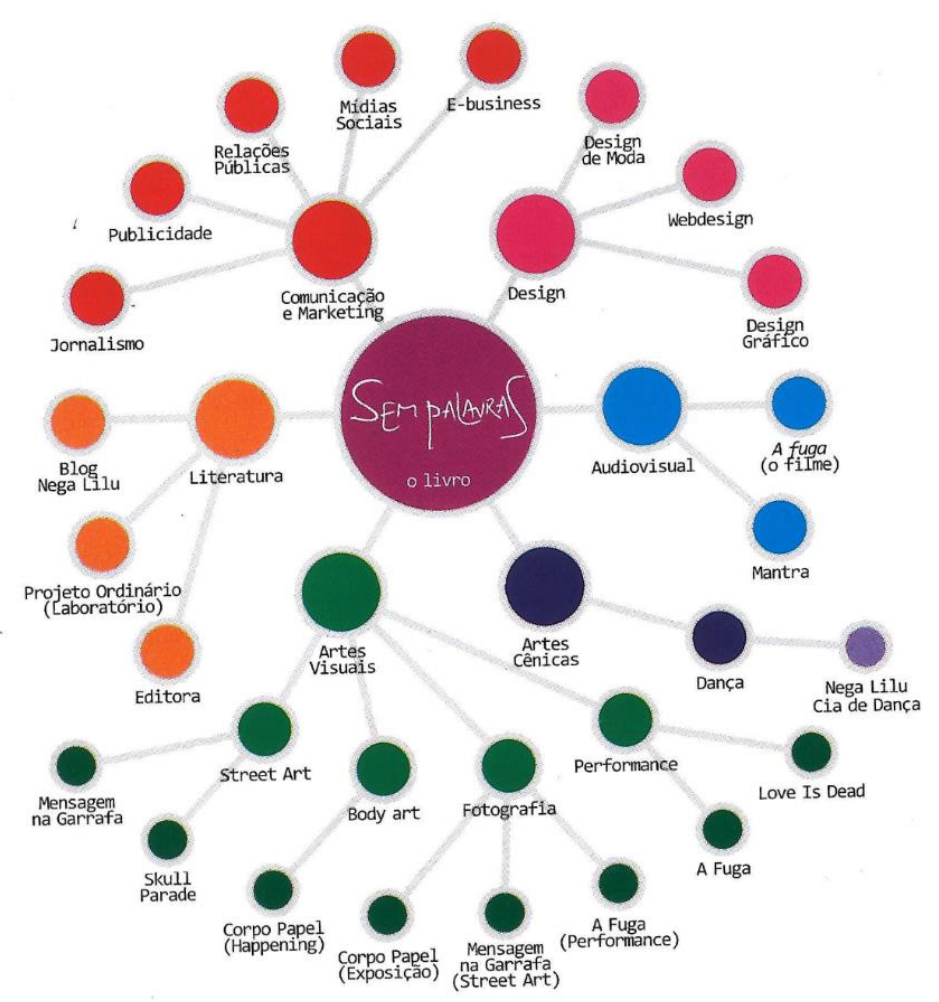

Figura 1 - Rede de atividades relativas ao conto "Sem palavras" Fonte: Mundim (2015).

O catálogo possui atualmente 21 títulos - dois traduzidos para a língua inglesa e um também disponível em audiolivro ${ }^{8}$-, dividido em oito selos, sendo eles: "Nega Lilu: literatura brasileira e projetos especiais; Eclea: biografias e registro da memória; Pantheon: poesia; Naduk: publicações experimentais e novos autores; Tuci: infantojuvenil; Ç3: e-books, audiobooks e similares". ${ }^{9}$ Com uma grande diversidade de gêneros e suportes, apesar de um relativo pequeno número de títulos, a linha editorial está apoiada em dois eixos: priorizar autores subrepresentados social e territorialmente no mercado editorial. Outro ponto fundamental é a busca pelo resgate e pela preservação da memória goiana, com títulos sobre a história do teatro, da dança e da culinária local.

O termo "sub-representado", presente no discurso da editora, faz referência aos sujeitos e grupos invisibilizados, percebidos em pesquisas como a supracitada de Dalcastagnè (2013). Mediante a perspectiva de um mercado editorial pouco plural, Larissa Mundim, em entrevista que nos foi concedida em 31 de maio de 2019, relata que "a prioridade da editora é a publicação de mulheres, mulheres negras, população LGBTQI", mas faz uma ressalva: "às vezes com uma iniciativa ou com um resultado menos efetivo do que algumas editoras que têm foco exatamente nisso, por exemplo, a Padê Editorial." Isso é perceptível quando analisamos que, entre os títulos publicados, cinco são de autoria de Larissa Mundim, seis de escritoras, cinco de escritores, quatro coletâneas e um catálogo de uma intervenção artística coletiva. Na entrevista, ela complementa: "nós temos, então, uma inserção um pouco mais difusa, mais aberta, e temos também como objetivo dar oportunidade aos novos autores".

A sub-representação decorre da interseção de diversas condições que levam um indivíduo à margem de um sistema dominante e hegemônico. E isso também ocorre quando falamos do

\footnotetext{
${ }^{8}$ Dados coletados em 19 de março de 2020. O livro Sem palavras (2013) está à venda no formato $e$-book, sendo também dividido em cinco capítulos traduzidos para o inglês. O título Sobreviventes do Césio 137 (2018) possui versões digital e física e Abracadabras: crio enquanto falo (2017) não possui versão impressa, apenas e-book e audiolivro.

${ }^{9}$ Disponível em: http://negalilu.com.br/a-editora/\#.XoD4onJv-bg. Acesso em: 29 mar. 2020.
} 
lugar que as editoras pesquisadas - pessoas e empreendimentos - ocupam no espaço social e territorial. Ana Elisa Ribeiro discorre sobre os poucos nomes de mulheres em compêndios sobre a história da edição, como O livro no Brasil, de Laurence Hallewell, obra de referência para esse tipo de pesquisa, o que demonstra o apagamento sistemático dessas mulheres. Além disso, a pesquisadora ressalta a ausência de informações substanciais sobre editoras que se encontram fora do eixo dominante:

O eixo Rio-São Paulo costuma ser tratado como sinônimo de Brasil, o que talvez seja explicável e compreensível, mas também tem suas perversas implicações. É preciso [...] que nos voltemos a outras regiões, onde mulheres editoras podem ter atuado e atuam, a despeito da seletividade geográfica, que sempre distorce narrativas, enterrando ocorrências relevantes e diversas (Ribeiro, 2019, p. 201).

Assim, o distanciamento da região Sudeste e dos principais circuitos da produção livreira convencional e independente - relega à margem diversos agentes do campo editorial e do literário. Isso ocorre devido à concentração de produtores, gráficas, cursos de especialização e eventos no eixo Rio-São Paulo, cidades consideradas "capitais culturais" e, por conseguinte, "capitais editoriais" (Muniz Jr., 2016, p. 33). Dessa maneira, a distribuição e venda de livros no Brasil possuem uma dinâmica complexa, na qual as editoras independentes precisam criar alternativas devido a seus parcos capitais financeiros, e essa realidade é ainda mais dificultosa para as casas distanciadas dos grandes centros. Partindo da perspectiva de autora periférica territorialmente, Larissa Mundim funda a casa editorial com o mote da militância pela visibilidade das produções de Goiás:

eu desejava publicar um romance ficcional diferentão, que tinha provavelmente uma rejeição enorme em função da arquitetura, da estética dele, às vezes até a temática... e também tem o fato de eu estar produzindo no interior do país, no Centro-Oeste, que é um espaço que a gente reconhece do ponto de vista territorial invisibilizado, assim como o Norte e Nordeste a despeito de muita produção, de muita produção qualificada. Então, para existir enquanto escritora, me autopubliquei. Assim que eu me vi formada, aprendemos a fazer livros, tínhamos o desejo, desde o princípio, de fazer livros lindos, mas em seguida a gente descobriu que isso era insuficiente, então a gente começou a fazer livros não apenas lindos. Começamos então a publicar outros autores, especialmente autoras do estado de Goiás buscando dar para eles oportunidade de existência no mercado editorial, mas a partir de uma proposta que fosse não convencional. [...] Então a Nega Lilu Editora surge no Brasil central com esse objetivo inicialmente: fazer livros lindos, depois fazer a conexão entre os autores locais para publicação e em seguida a circulação. ${ }^{10}$

Uma das iniciativas que busca fomentar a bibliodiversidade e dar espaço para vozes invisibilizadas pelo distanciamento geográfico foi a criação da Coleção E/Ou. Até o momento, foram lançados três editais para antologias específicas para novos autores goianos. No primeiro, aberto no período 2014/2015,11 foram selecionados 50 autores, publicados em duas antologias: As dores de Josefa (2016), com 27 contos e crônicas de 14 autores; e Os olhos do bilheteiro (2016), com 43 poemas de 17 novos escritores. O segundo, no período 2017/2018, deu origem à antologia Sobre gostar menos (2019), e traz 31 poetas selecionados pelo edital; e a O olhar inaudível (2020), com contos e crônicas de 21 autores, escritos em gêneros diversos, valorizando experimentações estéticas. O terceiro edital encerrou-se em 13 de abril de 2020.

Assim, 81 autores, até então à margem do mercado editorial, tiveram a oportunidade de ter seus textos publicados, e mais, foram publicados por uma instância legitimadora. Cabe lembrar que o editor detém o "poder de assegurar a publicação, ou seja, de fazer com que um texto e um autor tenham acesso à existência pública (Öfentlichkeit), conhecida e reconhecida. Essa espécie de 'criação' implica quase sempre uma consagração, uma transferência de capital simbólico [...]" (Bourdieu, 2018, p. 199). Ao transferir o capital simbólico para agentes que ocupam posições

\footnotetext{
${ }^{10}$ Em entrevista concedida em 31 de maio de 2019.

${ }^{11}$ Os editais são abertos em novembro/dezembro e encerram-se no primeiro trimestre do ano seguinte, por isso o período abrange dois anos.
} 
desprivilegiadas do campo, ou muitas vezes nem conseguem adentrá-lo, a Nega Lilu e a Padê Editorial criam um "efeito de chancela" que lhes permite buscar posições de maior prestígio.

Outro ponto relevante ao discutirmos o catálogo da editora é o esmero estético presente nas publicações, postulado por Larissa Mundim como "uma vontade de fazer livros lindos em uma proposta não convencional". Assim como a Padê Editorial, Nega Lilu faz parte de um segmento dentro do campo das independentes: editoras feirantes "esteticamente orientadas" por possuírem uma estreita interface com o universo do design e das artes visuais. O desafio comum é o de transpor para a superfície material elementos do conteúdo textual, de maneira que os exemplares sejam atrativos também por sua materialidade. Dessa forma, enquanto a Padê Editorial prioriza as publicações cartoneras - que, apesar de terem um baixo custo de produção, assemelham-se aos livros de artista, -, a Nega Lilu procura explorar o suporte físico produzindo tiragens maiores.

Um exemplo é Nádia Koller: memórias e receitas de Goyaz (2017), livro que traz o registro biográfico de uma pessoa trans nascida na década de 1930, cujas memórias são entremeadas às suas receitas de comidas goianas, e foi publicado por sua sobrinha Ana Christina da Rocha Lima. A cozinheira Nádia Koller, à época, registrou o feitio de pratos típicos até então transmitidos pela tradição oral, manuscrito em um caderno que anteriormente era usado para a contabilidade de um negócio familiar.

$\mathrm{Na}$ antiga Goyaz, as receitas eram motivo de intercâmbio, ciúme, boicotes e homenagens alquimias secretas que instauravam uma hierarquia na cidade. Algumas delas atravessaram séculos, herdadas e preservadas como joias de família em cadernos escritos à mão, um saber e um bem particular de cada Casa. [...] Faziam parte dos enxovais e eram herança cobiçada. A troca de receitas era um gesto de amizade e confiança, compartilhadas com parcimônia (Lima, 2017, p. 9).

Para transpor materialmente o texto, o livro de capa dura, no formato $38 \mathrm{~cm} \times 21 \mathrm{~cm}$, foi impresso com o miolo colorido. O texto apresenta uma biografia de cada pessoa que Nádia menciona nas receitas, com fotos antigas impressas em páginas inteiras. A tipografia e as cores dos títulos mudam quando saem do conteúdo memorialístico e passam para as receitas - que foram preparadas e fotografadas para o livro. Foram usados dois tipos de papel, no primeiro caderno, sulfite $90 \mathrm{~g} / \mathrm{m}^{2}$, no segundo, Chambril Avena $90 \mathrm{~g} / \mathrm{m}^{2}$. A capa possui um acabamento em tecido de algodão cru com listras em azul e vermelho, remetendo à padronagem de um caderno de contabilidade. A tiragem foi de mil exemplares e o livro teve o apoio de instâncias públicas: Fundo de Arte e Cultura de Goiás, Secretaria de Estado de Educação, Cultura e Esporte (Seduce) e Governo de Goiás. Atualmente é comercializado na loja virtual da editora por $\mathrm{R} \$ 65,00$.

Essa parceria com o governo está presente em grande parte dos livros publicados na Nega Lilu Editora, o que nos leva a refletir sobre o local que Larissa Mundim ocupa dentro do campo independente, haja vista as múltiplas atividades que ela desenvolve paralelamente. Integrante da Comissão Nacional de Incentivo à Cultura (CNIC), da Secretaria Nacional de Fomento à Cultura, ${ }^{12}$ seu trabalho na análise de projetos da Lei Rouanet proporciona um conhecimento ímpar sobre os mecanismos de apoio cultural da esfera pública. Fato perceptível em outras iniciativas que ela lidera ao longo do ano, entre estas, a feira e-cêntrica (nome que faz alusão ao fato de figurar fora do centro editorial do país), realizada anualmente desde 2018 em Goiânia, com o objetivo de aquecer o cenário local e levar publicadores de outras regiões do país. A edição de 2020 foi realizada nos dias 7 e 8 de março, na Vila Cultural Cora Coralina, com mais de 100 publicadores independentes de seis estados e do Distrito Federal.

É válido pontuar que as feiras de publicações independentes, além de serem espaços financeirizados, são, também, um lugar de construção de redes de sociabilidades e acúmulo de capital simbólico. Em Feira de publicações independentes: uma análise da emergência desses encontros em Belo Horizonte (2010-2017) e dos eventos Faísca - Mercado Gráfico e Textura (2017-2018), a partir de grupos focais com publicadores independentes de Belo Horizonte, Flávia Magalhães (2018)

\footnotetext{
${ }^{12}$ A secretaria atualmente está dentro do Ministério da Cidadania em função da extinção do Ministério da Cultura na gestão do presidente Jair Bolsonaro.
} 
concluiu que, nas feiras, "são essas trocas de capitais não financeiros que os estimulam a estar presentes. [...] as feiras são importantes por serem um dos poucos momentos que eles têm a oportunidade de conhecer outras pessoas que fazem publicações como as próprias" (2018, p. 130). Dessa forma, organizadores acabam por galgar lugares de maior prestígio e tornam-se agitadores culturais dentro do campo.

Ademais, a feira e-cêntrica é um desdobramento de um projeto maior, homônimo, que busca mapear, e conectar, por meio de uma plataforma digital, os publicadores independentes do Brasil e, assim, viabilizar alternativas para o mercado de pequenos produtores livreiros. Outra iniciativa de fomento permanente é a pequena livraria, chamada O Jardim, localizada em Goiânia, que comercializa apenas independentes e possibilita o acesso do leitor a estas produções fora do circuito das feiras. A postura de Larissa Mundim diante do cenário independente leva a crer que a jornalista ocupa a categoria de líder dentro das "quatro categorias ideal-típicas de agentes relacionados à (neo)gênese do 'independente'" descritas por Muniz Jr. (2016):

São articuladores, buscam a adesão de novos membros e promovem encontros entre os agentes, dando algo de coesão a tais agrupamentos. São frequentemente convocados a falar em cursos, palestras e mesas-redondas para compartilhar seus conhecimentos e opiniões sobre o universo de que fazem parte. Em vários casos, representam seus pares nas instâncias de diálogo e negociação com entes da vida setorial, política, militante etc., funcionando (de maneira ora duradoura, ora ocasional) como delegados ou despachantes dessas coletividades (Muniz Jr., 2016, p. 76).

A editora mobiliza autores, livreiros, editores e leitores em pequenas iniciativas ao longo do ano e está presente em feiras de outros estados - levando trabalhos próprios e de outras casas editoriais que têm dificuldade de participar de feiras mais distantes. Com frequência, é convidada para eventos do circuito, como o ciclo de palestras da Feira Miolo(s), realizada, anualmente, na Biblioteca Mário de Andrade, em São Paulo. Em 2019, sua fala "Estratégias para amenizar a invisibilidade da produção gráfica-literária fora dos centros" ${ }^{\prime 13}$ trouxe contribuições para editores feirantes e frequentadores, reiterando o perfil de líder e militante dessa cena tão heterogênea.

\section{Considerações finais}

O campo editorial independente é um espaço heterogêneo, seja pelas múltiplas significações que o termo comporta, seja pela diversidade de produtores e produtos que aí se encontram. Como todo campo, neste ocorrem disputas internas por um lugar de prestígio. Entretanto, na edição independente, percebemos, sobretudo, uma grande rede de sociabilidade e interdependência, imprescindível para vencer as dificuldades que a distribuição e a venda apresentam para pequenos editores.

Com o estudo de caso da Padê Editorial e da Nega Lilu Editora, entendemos como estas pequenas casas editoriais têm fomentado a bibliodiversidade e usado o termo "independente" como um adjetivo político, ao dar voz a discursos dissonantes e não hegemônicos no mercado editorial (Muniz Jr., 2016). Ambas iniciaram suas empreitadas movidas pelo ensejo da autopublicação e, posteriormente, com o acúmulo de capital simbólico, começaram o processo de "consagrar" autores e obras (Bourdieu, 2001) que passam à margem de editoras com foco em "livros-produtos", definidos por Colleu (2007). Elas possuem o experimentalismo estético como pano de fundo de suas produções e comercializam, principalmente, por meio das feiras de publicações independentes, não prescindindo do apoio governamental em parte de suas iniciativas. Tatiana Nascimento dos Santos, Bárbara Esmenia e Larissa Mundim são mulheres editoras do Brasil central que resistem, assim como seus autores e suas obras, em um campo literário que, conforme reiterado neste artigo, mostra-se um espaço excludente para vozes historicamente abafadas.

\footnotetext{
${ }^{13}$ Disponível em: https://www.facebook.com/Lote42/videos/feira-miolo-s-2019/2126764867424535/. Acesso em: 23 mar. 2020.
} 


\section{Referências}

BOURDIEU, Pierre (2001). A produção da crença: contribuição para uma economia dos bens simbólicos. Porto Alegre: Editora Zouk.

BOURDIEU, Pierre (2005). As regras da arte: gênese e estrutura do campo literário. São Paulo: Cia. das Letras.

BOURDIEU, Pierre (2018). Uma revolução conservadora na edição. Tradução de José de Souza Muniz Jr. e Luciana Salazar Salgado. Revista Política E Sociedade, Florianópolis, v. 17, n. 39, p. 198-249. Disponível em: https:// bit.ly/3p3YaOM. Acesso em: 12 fev. 2019.

COLLEU, Gilles (2007). Editores independentes: da idade da razão à ofensiva? Rio de Janeiro: Libre.

DALCASTAGNÈ, Regina (2012). Literatura brasileira contemporânea: um território contestado. Vinhedo: Editora Horizonte.

KILOMBA, Grada (2019). Memórias da plantação: episódios de racismo cotidiano. Rio de Janeiro: Cobogó.

LIMA, Ana Christina da Rocha Lima (2017). Nádia Koller: memórias e receitas de Goyaz. Goiânia: Nega Lilu.

LUGONES, María (2019). Rumo a um feminismo decolonial. In: HOLLANDA, Heloisa Buarque de (Org.). Pensamento feminista: conceitos fundamentais. Rio de Janeiro: Bazar do Tempo. p. 357-377.

MAGALHÃES, Flávia Denise Pires de (2018). Feira de publicações independentes: uma análise da emergência desses encontros em Belo Horizonte (2010-2017) e dos eventos Faísca - Mercado Gráfico e Textura (20172018). 2018. 160 f. Dissertação (Mestrado em Estudos de Linguagens) - Centro Federal de Educação Tecnológica de Minas Gerais, Belo Horizonte.

MUNDIM, Larissa (2011). A perversão do enigma. Nega Lilu: experiência literária coletiva, Goiânia, 13 jan. Blog. Disponível em: http://negalilu.com.br/category/blog-nega-lilu

MUNDIM, Larissa (2015). Operação Kamikaze. Goiânia: Nega Lilu Editora.

MUNDIM, Larissa; PRADO, Valentina (2013). Sem palavras. Goiânia: Nega Lilu Editora.

MUNIZ JÚNIOR, José de Souza (2016). Girafas e bonsais: editores “independentes" na Argentina e no Brasil (1991-2015). Tese (Doutorado em Sociologia) - Universidade de São Paulo, São Paulo.

NASCIMENTO, Tatiana (2018). Entrevista. In: LEMES, Ana Emília. Editoras lésbicas brasileiras: algumas iniciativas no mercado editorial. Trabalho de conclusão de curso (Graduação em Letras) - Centro Federal de Educação Tecnológica de Minas Gerais, Belo Horizonte.

NOËL, Sophie (2018). La edición independiente crítica: compromisos políticos e intelectuales. Villa María: Eduvim.

POLESSO, Natália Borges (2018). Geografias lésbicas: literatura e gênero. Criação e Crítica, n. 20, p. 3-19. Dossiê Sáfico.

RIBEIRO, Ana Elisa (2019). Boitempo Editorial e Ivana Jinkings: um quarto de século de uma editora de esquerda no Brasil. Pontos de Interrogação, Alagoinhas, v. 9, n. 1, p. 201-226, jan.-jun.

SILVA, Nathanael Araújo da (2016). As pessoas dos livros e os livros das pessoas: uma etnografia sobre a produção e circulação de obras LGBTs. Dissertação (Mestrado em Ciências Sociais) - Universidade Federal Rural do Rio de Janeiro, Rio de Janeiro.

THOMPSON, John B (2013). Mercadores de cultura: o mercado editorial no século XXI. São Paulo: Ed. Unesp. 